\title{
Status of Anxiety Disorders among Elderly People in a Selected Urban Area in Bangladesh
}

\author{
Omma Hafsa Any ${ }^{1}$, Sharna Moin², Mahbuba Akter ${ }^{3}$, Khandakar Nadia Afreen $^{4}$, \\ Manas Kanti Mazumder ${ }^{5}$
}

\begin{abstract}
${ }^{1}$ Associate Professor, Head of the Department of Pharmacology \& Therapeutics, Army Medical College, Jashore, Bangladesh; ${ }^{2}$ Assistant
Professor, Department of Anatomy, Army Medical College, Jashore, Bangladesh; ${ }^{3}$ Associate Professor, Department of Anatomy, ZH Sikder Medical College, Dhaka, Bangladesh; ${ }^{4}$ Associate Professor, Department of Physiology, ZH Sikder Medical College, Dhaka, Bangladesh; ${ }^{5}$ Medical Officer, Department of Anaesthesia Analgesia and Intensive care Medicine, Bangabandhu Sheikh Mujib Medical University, Dhaka, Bangladesh
\end{abstract}

[Received on: 22 April 2021; Accepted on: 12 May 2021; Published: 1 July 2021]

\begin{abstract}
Background: Anxiety disorders are reported in the different age group of people in the urban area. Objective: The purpose of the present study was to determine the level of anxiety disorder among urban elderly people. Methodology: This cross-sectional community based study was carried out from January to December 2016 at Bakolia, Chawkbazar urban area of Chittagong, Bangladesh.The individuals who were aged 60 years and above were interviewed by using convenient sampling. Face to face interview was done with semi structural questionnaire. Results: Out of 300 respondents female respondents were higher in number which was $168(56 \%)$ respondents; however, $71.7 \%$, respondents were in 60 to 69 age groups. Majority of respondents did not have any income which was 72(60.0\%) subjects. Most of the respondents were suffering from hypertension which was $198(66.0 \%)$ respondents. In urban areas $82(27.3 \%)$ subjects did not have anxiety disorder, while $133(44.3 \%)$ respondents had mild anxiety disorder, $63(21.0 \%)$ respondents had moderate and $22(7.3 \%)$ respondents had severe anxiety disorder. Furthermore, $192(64.0 \%)$ respondents who were concerned about their finance had anxiety disorder. $160(53.3 \%)$ were concerned about their health had anxiety disorder. Conclusion: In conclusion majority urban dwelling elderly people are suffering from anxiety disorders. [Journal of National Institute of Neurosciences Bangladesh, July 2021;7(2):137-141]
\end{abstract}

Keywords: Anxiety disorder; elderly people; urban; mental health

Correspondence: Dr.Omma Hafsa Any, Associate Professor, Head of the Department of Pharmacology \& Therapeutics, Army Medical College, Jashore, Bangladesh; Email: omma.hafsa.anee@gmail.com; Cell no.: +8801707543140

Conflict of interest: There is no conflict of interest relevant to this paper to disclose.

Funding agency: This research project was not funded by any group or any institution.

Contribution to authors: Any OH, Moin S, Akter M were involved in protocol preparation, data collection and literature search and manuscript writing. Afreen KN, Mazumder MK was involved in preparation and revision of this manuscript.

How to cite this article: Any OH, Moin S, Akter M, Afreen KN, Mazumder MK. Status of Anxiety Disorders among Elderly People in a Selected Urban Area in Bangladesh. J Natl Inst Neurosci Bangladesh, 2021;7(2): 137-141

Copyright: (C2021. Any et al. Published by Journal of National Institute of Neurosciences Bangladesh. This article is published under the Creative Commons CC BY-NC License (https://creativecommons.org/licenses/by-nc/4.0/). This license permits use, distribution and reproduction in any medium, provided the original work is properly cited, and is not used for commercial purposes.

\section{Introduction}

Global population aging, due to fertility decline and rising life expectancy, has extensive consequences ${ }^{1}$, In 2017, an estimated 962 million people were aged 60 or over comprising $13 \%$ of the global population which is predicted to rise to 1.4 billion (16.5\%) by 2030 and 2.1 billion $(20 \%)$ by $2050^{2}$. Anxiety is an adaptive emotional reaction that prepares both young and old for coping, through resource mobilization or avoidance, with an anticipated or on-going event that is perceived as noxious or threatening. Although anxiety disorders are the most prevalent disorders among older adults, we known far less about the clinical characteristics, course, treatment, and prognosis of these disorders relative to others, such as late-life depression. Late life anxiety increases the risk for mortality ${ }^{3,4}$ and onset of disability even in high-functioning older adults 5 .

Anxiety is an adaptive emotional reaction that prepares both young and old for coping, through resource mobilization or avoidance, with an anticipated or on-going event that is perceived as noxious or threatening. Such anxiety can become pathological when 
excessive, distressing, and significantly interferes with an individual's ability to hold and fulfill multiple life roles like occupational, family, and social. Several diagnostic categories of anxiety disorders are described in the Diagnostic and Statistical Manual, $4^{\text {th }}$ Edition (DSM-IV) of the American Psychiatric Association ${ }^{6}$ and are distinguished along several dimensions, such as cognitive content (e.g., types of thoughts), eliciting stimuli, as well as symptom onset and duration. On the whole, anxiety disorders are more prevalent relative to other psychiatric disorders, such as mood disorders, in both young ${ }^{7}$, and older populations ${ }^{8,9}$. Despite the frequency of anxiety disorders and findings that older adults with anxiety disorders and anxiety symptoms report significant decrements in health and quality of life (physical activities, psychological well-being) as well as increased health service utilization and dissatisfaction with health services ${ }^{10}$, we know surprisingly little about anxiety disorders in late life.

Some authors categorize anxiety as primary and secondary ${ }^{11}$, in which primary anxiety results from psychiatric conditions, and secondary anxiety has a medical causes. The health of the elderly differs from country to country affected by socioeconomic and environmental attributes, care of the elderly therefore involves a holistic combination of health care, socioeconomic care and the provision of suitable environment. The present study was conducted in urban slum areas to determine the level of anxiety disorder among urban elderly people and its epidemiological correlates among elderly people residing in Bakolia, Chawkbazar. Chittagong, Bangladesh.

\section{Methodology}

This cross-sectional community based study was carried out from January to December 2016 at Bakolia, Chawkbazar urban area of Chittagong, Bangladesh. Elderly subjects who were aged 60 years and above, of both the sexes were contacted through house-to-house visits for the data collection. In each household, the head of the family or another responsible adult was contacted. The nature and the purpose of the study was explained to the subject. If more than two persons of age 60 years and above were present in the same house, two persons of the opposite sex like one from either sex were selected as the study subjects and between the persons of the same sex group, the elder person was given preference and was selected as the study subject. Thus, a maximum of two persons were taken from one house as the study subjects. If the particular elderly person was not present at the time of the survey, the house was revisited. The elderly persons who were not available in spite of repeated visits to their houses and those who did not give their consents for participation in the study were not included in this study. The information regarding their ages was cross checked by asking their children's age(s), with respect to some major events and by verifications from records like National ID card, etc. The identified 300 older subjects were interviewed face to face in their local languages and they were examined by using a pre-tested, pre-structured, study questionnaire. The first part for general information and second part for anxiety disorder assessment by Geriatric Anxiety Scale (GAS), then data were analyzed and Geriatric Anxiety Scale to assess anxiety status. The GAS was a 30 -item self-reported anxiety scale designed for use of older adults. First 25 items were used for scoring; last 5 items were used to assess common aspects of worry among older adults. The respondents were asked to answer the questions in reference to what they felt in past one week. Response for each item ranged from 0 to 3.0 for not at all, 1 for sometimes, 2 for most of the time and 3 for always. Total score was obtained by adding the scores of the items 1 to 25. Normal was considered in 1 to 11 , mild anxiety in 12 to 21 , moderate anxiety in 22 to 27 and severe anxiety in 28 to 54 . The elderly peoples of both sexes were belongs to 60 and above 60 years ages and their questionnaires were used as source of data. None of the participants were undergoing medical/neurological or psychiatric treatment at the time of assessment. The information in the questionnaire was then used complete a customized proforma. The recorded information was name, age, sex, marital status, educational and socioeconomic condition, whether any other drugs or treatment was taken for illness. Data was compiled, presented and appropriate statistical test was done in this study for drawing an appropriate conclusion. Statistical analysis was done with Microsoft Office Excel 2007. The data was expressed as percentage, mean and total number.

\section{Results}

A total three hundred (300) respondents were included in this study. The socio-demographic status of the elder people was summarized in the table 1 . Results show female were $168(56 \%)$ respectively more than male was $132(44 \%)$ cases.

Out of 300 respondents $82(27 \%)$ subjects did not have anxiety disorder, while $133(44.33 \%)$ subjects had mild anxiety disorder, 63(21\%) subjects had moderate and $22(7.33 \%)$ subjects had severe anxiety disorder (Table 2).

Most of the respondent $66 \%$ subjects were suffering from Hypertension. Among them others $7.3 \%$ subjects were suffering from peptic ulcer disease, parkinsonism, 
hearing problem, paralysis, piles/fistula (Table 3).

Table 1: Distribution of the Respondents according to Gender $(\mathrm{n}=300)$

\begin{tabular}{lcc}
\hline Gender & Frequency & Percent \\
\hline Male & 132 & 44.0 \\
Female & 168 & 56.0 \\
Total & $\mathbf{3 0 0}$ & $\mathbf{1 0 0 . 0}$ \\
\hline
\end{tabular}

Table 2: Distribution of the Respondents by their Anxiety Disorder $(\mathrm{n}=300)$

\begin{tabular}{lcc}
\hline Anxiety Score & Frequency & Percent \\
\hline Normal & 82 & 27.3 \\
Mild & 133 & 44.3 \\
Moderate & 63 & 21.0 \\
Severe & 22 & 7.3 \\
Total & $\mathbf{3 0 0}$ & $\mathbf{1 0 0 . 0}$ \\
\hline
\end{tabular}

Anxiety scale by Geriatric anxiety scale

Table 3: Distribution of the Respondents by their Chronic Disease $(n=300)$

\begin{tabular}{lcc}
\hline Medical condition & Frequency* $^{*}$ & Percent \\
\hline associated with anxiety & 198 & 66.0 \\
Hypertension & 153 & 51.0 \\
Diabetes mellitus & 109 & 36.3 \\
Heart disease & 116 & 38.7 \\
Osteoarthritis & 78 & 26.0 \\
Dental problem & 42 & 14.0 \\
Bronchial Asthma & 67 & 22.3 \\
Cataract & 16 & 5.3 \\
Hormonal disease & 22 & 7.3 \\
Others & & \\
\hline
\end{tabular}

*Multiple responses

Table 3: Distribution of the Respondents by their Chronic Disease $(n=300)$

\begin{tabular}{|c|c|c|c|}
\hline \multirow[t]{2}{*}{ Variable } & \multicolumn{3}{|c|}{ Anxiety disorder } \\
\hline & No & Yes & Total \\
\hline \multicolumn{4}{|l|}{ Gender } \\
\hline - Male & $34(25.7 \%)$ & $98(74.2 \%)$ & $132(44.0 \%)$ \\
\hline - Female & $48(28.6 \%)$ & $120(71.4 \%)$ & $168(56.0 \%)$ \\
\hline \multicolumn{4}{|c|}{ Concerned about finance } \\
\hline - Not at all & $24(8.0 \%)$ & $26(8.67 \%)$ & $50(16.67 \%)$ \\
\hline - Yes & $58(19.3 \%)$ & $192(64.0 \%)$ & $250(83.3 \%)$ \\
\hline \multicolumn{4}{|c|}{ Concerned about health } \\
\hline - Not at all & $27(9.00 \%)$ & $58(19.33 \%)$ & $85(19.33 \%)$ \\
\hline • Yes & $55(18.33 \%)$ & $160(53.33 \%)$ & $215(71.67 \%$ \\
\hline \multicolumn{4}{|c|}{ Concerned about children } \\
\hline - Not at all & $20(6.67 \%)$ & $36(5.33 \%)$ & $56(18.67 \%)$ \\
\hline • Yes & $62(20.67 \%)$ & $182(60.67 \%)$ & $244(81.33 \%$ \\
\hline \multicolumn{4}{|c|}{ Afraid of dying } \\
\hline - Not at all & $31(10.33 \%)$ & $56(18.67 \%)$ & $87(29.00 \%)$ \\
\hline - Yes & $51(17 \%)$ & $162(54 \%)$ & $213(77.00 \%$ \\
\hline \multicolumn{4}{|c|}{ Afraid of becoming burden to family } \\
\hline - Not at all & $44(14.67 \%)$ & $71(23.67 \%)$ & $115(38.33 \%)$ \\
\hline • Yes & $38(12.67 \%)$ & $147(49 \%)$ & $185(61.67 \%$ \\
\hline
\end{tabular}

Table 4 showed Association of anxiety disorder between socio-demographic status and geriatric anxiety scale in urban area

\section{Discussion}

The World Health Organization defines health as "a state of complete physical, mental, and social well-being and not merely the absence of disease or infirmity" Because mental health is essential to overall health and well-being, it must be recognized and treated in all older adults, with the same urgency as physical health. For this reason, mental health is becoming an increasingly important part of the public health mission.

Bangladesh is currently undergoing a demographic transition and the proportion of the population 60 years and older is rapidly increasing. It is increasingly acknowledged that anxiety disorders are frequent disorders in late life and of paramount prognostic impact as an under recognized cause of mental and physical disability as well as a potential catalyst of the mortality risk in the elderly. Late -life anxiety might be understood as the result of several simultaneously working processes. On one hand, aging is associated with age-specific psychosocial risk factors for anxiety like living alone, physical illness and disability, or cognitive decline.

This cross sectional observational study was conducted in Bakolia, Chawkbazar in urban area of Chittagong, Bangladesh with an aim to determine the level of Anxiety disorder among urban elderly people, identify anxiety disorder among elderly urban people, find out the factor associating anxiety disorder among urban elderly people, and detect socio-demographic characteristics of participants.

A total 300 respondents were included in this study. Female were majority $168(56 \%)$ than male which were 132(44\%). Another study shows a significantly higher prevalence of depression was found in females $(56.5 \%)$ than in males $(37.5 \%)$, which is very similar to this study 16 , another study shows that majority of the participant males were $53.6 \%$ and female were $46.4 \%$, which is not similar to this study ${ }^{12}$. And their average age group was 68.10. Majority 56 (46.7\%) in urban were housewife, Another study reveals that about $20 \%$ of the respondents were cultivators, $21 \%$ of them businessmen, $10.5 \%$ ex-service holder, 14\% labor, 15\% unemployed and $21 \%$ of them were housewives ${ }^{13}$. This is not similar to this study.

The prevalence of anxiety disorder was found $65.8 \%$ in urban area. Another study found that the prevalence of anxiety was $55.5 \%$ which is similar to this study ${ }^{14}$. These study findings were similar to the findings of Bryant et al 
who did a systematic review of literature on anxiety in people over 60, published between 1980 and 2007 and he found that prevalence of anxiety symptoms ranged from $15 \%$ to $52.3 \%$ in community samples and $15 \%$ to $56 \%$ in clinical samples ${ }^{13}$. In this study we found that there was association between concern about finance and anxiety disorder among urban elderly people $192(64.00 \%)$ of urban elder people who were concerned about finance. Another study showed the factors of worry among the respondents where $44.9 \%$ elders were concerned about their finance most of the time or always which is similar to this study ${ }^{12}$. In this study, large number of the respondents were found dependent on their family members like son, daughter and relatives. Urban elder people were more concerned about their children which were $182(60.67 \%)$ and had no association with anxiety disorder. Another study showed that $39.2 \%$ of elders were worried about their children most of the times or always which is not similar to this study ${ }^{12}$.

There was association between afraid of dying and anxiety disorder among urban elderly people 162(54\%) of peoples were afraid of dying. Another study revealed that only $11.1 \%$ elders were afraid of dying most of the times or always which was not similar to this study ${ }^{12}$. There was association between afraid of becoming burden to family which was147 (49\%) and anxiety disorder among urban elderly people. Another study found that $27 \%$ geriatric populations were afraid of becoming the burden to the family and friends most of the times or always which was not similar to this study ${ }^{12}$. Some of the reasons for the sudden increase in the prevalence after the age of 69 years might be an increased economical and physical dependency, loss of the spouse, negligence by the family members and loss of self esteem. Similar findings were found in another study ${ }^{17,18}$. These experiences could increase their levels of stress and lead to a decrease in the resources that individuals feel they have in dealing with their daily lives ${ }^{15}$.

Growth in the elderly population means a direct increase in age-related diseases such as dementia and poor mental health outcomes such as depression, anxiety, suicide and serious constraints on the quality of life among elderly individuals. The most common chronic diseases found among the elderly were hypertension, diabetes mellitus, stroke and other non-communicable diseases are leading cause of morbidity, hospitalization and disability among the elderly all over the world. General health problems of aged is not merely medical, it is physical, mental, economical and socio-cultural.

As the issues of health and above all, illness or disability in old age, is a matter of increasing public concern, a perspective on healthy aging is crucial when it comes to identify, design and implement appropriate strategies to meet the growing needs of the population ${ }^{16}$. In Bangladesh, the geriatric population is gradually increasing and their problems are also increasing day by day. So more attention and extensive health care services, especially for mental health are being felt needed for the aged people.

\section{Conclusion}

There is great evidence of a rise in morbidity, mortality, hospitalization and loss of functional status related with common mental disorders in elderly patients. As the number of aged in our population is increasing, many of the traditional life sustaining and fostering influences for the elderly have been eroding. The present study revealed common anxiety disorders and severity of anxiety and they need more support from family as well as society and country to improve their health problem. At the same time, Bangladesh also lacks appropriately trained adequate number of human resources for mental health services. Contrary to popular belief, it must be fully recognized by policy makers and planners alike that mental illness constitutes a serious threat to national health.

\section{References}

1. Harper S. Economic and social implications of aging societies. Science 2014;346(6209):587-91

2. United Natins. World Populatin Prospects: The 2017 Revision, Key Findings and Advance Tables Ney York: United Natins, Department of Economic and Social Affirms PD; 2017. Contract No.: Working Paper No. ESA/P/WP/248. Available from: htts://esa.un.org/unpd/wpp/ Publicatins/Files/WPP2017_KeyFindings.pdf

3. Allgulander C, Lavori P. Causes of death among 963 elderly patients with "pure" anxiety neurosis in Stockholm and in patients with depressive neurosis or both diagnoses. Compr Psychiatry. 1993;34: 299-302

4. Van Hout H, Beekman A, de Beurs E, Comijs H, van Marwijk H, de Haan M, et al. Anxiety and the risk of death in older men and women. Br. J. Psychiatry. 2004;185: 399-404

5. Seeman T, Berkman L, Charpentier P, Blazer D, Albert M,Tinetti M. Behavioral and psychosocial predictors of physical functioning: MacArthur Studies of Successful Aging. J Gerontol A BiolSci Med Sci. 1995;50:177-183

6. American Psychiatric Association. Diagnostic and statistical manual of mental disorders. 4th ed. Washington, D.C.: Author; 1994

7. Regier DA, Boyd JH, Burke JD, Rae DS, Myers JK, Kramer M, et al. One-month prevalence of mental disorders in the United States. Arch Gen Psychiatry 1988;45:977-86

8. Beekman ATF, Bremmer MA, Deeg DJH, van Balkom AJLM, Smit $\mathrm{JH}$, de Beurs E, et al. Anxiety disorders in later life: a report from the 
Longitudinal Aging Study Amsterdam. Int J Geriatr Psychiatry 1998;13: 717-26

9. Beekman ATF, Deeg, DJH, van Tilburg T, Smit JH, Hooijer C, van Tilburg W. Major and minor depression in later life: a study of prevalence and risk factors. J Affect Disord 1995;36: 65-75

10. de Beurs E, Beekman ATF, van Balkom AJL, Deeg DJH, van Dyck $\mathrm{R}$, van Tilburg W. Consequences of anxiety in older persons: its effect on disability, well-being, and use of health services. Psychol Med 1999;29: 583-93

11. Cassem Ell. Depression and anxiety secondary to medical illness. Psychiatr Clin North Am 1990;13:597-612

12. World Health Organization (1948). Constitution of the World Health Organization. Available at: http://www.who.int/governance/eb/ who_constitution_en.pdf (accessed June 23, 2008)

13. Haque J,Alam R 2003, Health Problems of the Geriatric People: A Community Based Study in a Rural Area in Bangladesh 16(1): 15-19 14. Ritchie k, Artero S, Beluche I, Iancelin M, MannA; prevalence of $\mathrm{dsm}^{\wedge}$ iv psychiatric disorder in the French elderly population. British journal of psychiatry. 2004; 184:147-52

15. Sachs-Ericsson, N., Kendall-Tacket, K. A., Sheffler, J., Arce, D., Rushing, N. C., and Cosentino, E. (2014). The influence of prior rape on the psychological and physical health functioning of older adults. Aging Mental Health 18, 717-730.

16. Djukanovic, I., Sorjonen, K., and Petersona, U. (2015). Association between depressive symptoms and age, sex, loneliness and treatment among older people in Sweden. Aging Ment. Health 19, 560- 568.

17. Swarnaltha N.The Prevalence of Depression among the Rural Elderly in Chittoor District, Andhra Pradesh.J Clin Diagn Res. 2013 Jul; 7(7): 1356-1360

18. Jariwala Vishal, Bansal RK, Patel Swati, Tamakuwala Bimal. A study of depression among aged in Surat city. National Journal of Community Medicine. 2010;1(1):47-49

19. Rajkumar AP, Thangadurai P, Senthilkumar P, et al. Nature, prevalence and factors associated with depression among the elderly in a rural south Indian community. International Psychogeriatrics. 2009;21:372-78 